\title{
MÉTRICA PROPOSTA PARA VALORAÇÃO DE ÁREAS AMBIENTAIS
}

\author{
Lucas José Machado dos Santos* \\ Maisa de Souza Ribeiro**
}

RESUMO: O objetivo é propor a métrica de valoração de Reservas Legais (RL) e Áreas de Preservação Permanente (APP) em propriedades agrícolas, com a premissa de que as áreas ambientais estejam no seu estado natural e ainda livres dos efeitos antrópicos. Foi utilizado o método de Custo de Oportunidade (CO), Contabilidade Emergética e Curva Ambiental de Kuznets (CAK). A métrica constitui-se da soma do valor do CO ao Valor Total do Bioma (VTB). O valor do CO é descontado pelo risco do negócio analisado. O VTB é estimado pela Contabilidade Emergética, considerou-se a área do hectare preservado, ou conservado, em RL e/ou APP, e a área remanescente de cada bioma terrestre brasileiro estudado. O VTB é ponderado pela CAK e esta, estimada pela variação dos preços da cultura agrícola analisada. Visando à sua validação, estimou-se a área preservada APP's, ou conservada em hectares de RL de cada bioma terrestre brasileiro, referente às dez culturas agrícolas que possuem maior área plantada. Das culturas utilizaram-se dados sobre os valores brutos de produção, a variação dos preços em média nacional e a extensão territorial das unidades federais brasileiras, assim como dados dos biomas terrestres brasileiros, referentes às suas áreas totais e áreas remanescentes preservadas. Aplicou-se a métrica em biomas preservados em nível nacional e sobre cinco culturas reais de dados coletados de empresas agrícolas.

PALAVRAS-CHAVE: Contabilidade; Contabilidade emergética; Custo de oportunidade.

\section{MEASUREMENTS FOR THE VALORIZATION OF ENVIRONMENTAL AREAS}

ABSTRACT: Valorization measurements of Legal Reserves (LR) and Permanent Preservation Areas (PPA) on farms are undertaken presupposing that green areas are in their natural state and free from human activities. Opportunity Costs (OC), Energetic Account and Kuznet's Environmental Curve (KEC) were employed.

\footnotetext{
Faculdade de Economia, Administração e Contabilidade de São Paulo (campus Ribeirão Preto) FEA USP-RP, Brasil.E-mail: lucasjmsantos@yahoo.com.br

** Doutora em Controladoria e Contabilidade. Docente permanente do Programa de Pós-Graduação da FEA-RP/ USP, Brasil.
} 
Measurement comprised the sum of CO and Biome Total Value (BTV). OC is subtracted due to the business risk analyzed. BTV is estimated by Energetic Account, taking into consideration the preserved or conserved area in LR and/or PPA, and the remaining area of each Brazilian biome. BTV is calculated by KEC estimated by price variation of the culture under analysis. PPAs or conservation areas were estimated in LR hectares of each Brazilian biome with regard to ten agricultural cultures with the largest area. Data on the gross production rates of cultures, mean national price variation and territorial extension of the Brazilian federal units were employed, coupled to data on Brazilian biomes with regard to total areas and preserved remnant areas. Measurements of preserved biomes were thus applied at national level and with regard to five cultures retrieved from data by agriculture firms.

KEY WORDS: Accounts; Energy accounting; Opportunity costs.

\section{INTRODUÇÃO}

Chiabai et al. (2011) dizem que a avaliação econômica do meio ambiente tem atingido gradualmente a agenda política internacional, pois a comunidade científica está cada vez mais empenhada em subsidiar a ação política no sentido de uma utilização sustentável dos recursos florestais.

Porém a maior dificuldade nos métodos de valoração ambiental está na complexidade com que alguns são aplicados. O valor auferido de Reservas Legais (RL) e Áreas de Preservação Permanentes (APP), com a métrica proposta neste trabalho, pretende ser menos subjetivo, mais acurado e comparável conforme o bioma, podendo com isso suscitar sua utilização para identificação dos benefícios esperados. Portanto, qual o valor das áreas de RL e APP's?

O objetivo desta pesquisa foi desenvolver uma métrica que permitisse definir um valor para remuneração da preservação dos biomas terrestres brasileiros em APP's, ou em conservação em RL's em propriedades agrícolas, levando em consideração, com intuito de facilitar a aplicação da métrica proposta por este trabalho, a premissa de que essas áreas estariam no seu estado natural, puro e ainda livre dos efeitos das ações humanas.

A proposta é que existam um valor pré-estabelecido para cada bioma nacional (Amazônia, Cerrado, Mata Atlântica, Caatinga, Pampa e Pantanal), valorado pela contabilidade emergética, idealizada por Odum (1996), e o agente agropecuário, 
por exemplo, o setor sucroalcooleiro, que deve preservar determinado hectare de cerrado, utilizará o valor por hectare desse bioma dentro de sua propriedade e o somará ao seu custo de oportunidade, pois as áreas de preservação, ou conservação, em RL e APP's são de preservação compulsória.

A pesquisa é motivada pela ênfase que temas ambientais vêm tomando em diversas ciências e pela exploração dos métodos de valoração ambiental como mecanismos de estímulo à preservação ambiental. Também se justifica pela necessidade de se encontrar uma maneira de facilitar os processos de tomada de decisões referentes às questões ambientais, provendo os agentes de informações sobre o meio ambiente, traduzidas em valores monetários.

Sobre valoração e contabilidade ambiental, Ferreira (2011) relata que a valoração ambiental é um dos aspectos mais críticos da contabilização, pois, não tendo valores monetários para os bens ou serviços ambientais, os profissionais de contabilidade se deparam com incertezas com quais não estão acostumados.

A contabilidade ambiental, como segmento da contabilidade tradicional, requer acurácia nos valores mensurados para preservação do meio ambiente, ou seja, contabilizar valores que possam apresentar subjetividade, incertezas e vieses viria na contramão das premissas de mensuração contábil, mas deixar esses valores fora da mensuração também levaria a uma subestimação. Definir uma métrica que, mesmo que não reflita o valor total da preservação ou conservação, mas consiga capturar com menos incertezas o valor do bioma, podendo servir como um ponto de partida de negociações de mercado e tomada de decisões, quando, depois de feita a estimativa, indivíduos teriam uma referência para expressarem seus desejos de pagar ou de receber pela preservação ambiental.

Essa nova métrica poderia atender às PNMC (Política Nacional de Mudanças Climáticas) e PEMC (Política Estadual de Mudanças Climáticas), instituídas pela lei $\mathrm{n}^{\circ}$ 12.187, de 29 de dezembro de 2009, que preveem compensações a preservadores, ao REDD-plus e à nova proposta de mudança do Novo Código Florestal, a qual contempla o item de pagamento por serviços ambientais (PSA). Conforme SoaresFilho (2014), proprietários que detêm áreas de florestas além do exigido pela lei poderão negociar no mercado financeiro os títulos conhecidos como Cotas de Reservas Ambientais (CRA), o que ofereceria uma alternativa econômica para a preservação. 
Foram conciliados, na métrica, os métodos de Custo de Oportunidade e Contabilidade Emergética.

\subsection{REFERENCIAL TEÓRICO}

Duas correntes de pensamento se desenvolveram a partir da consideração da importância do capital natural em suportar o capital manufaturado e o seu possível colapso. São elas a Teoria Econômica Ambiental Neoclássica (TEAN) e a Teoria Econômica Ecológica (TEE).

"Os economistas ambientais falam que valorizar o meio ambiente, significa dar-lhe um preço de mercado com base na oferta e demanda e nas preferências individuais" (BEDER, 2011), ou seja, a valoração ambiental seria dada pela curva de oferta e demanda de cada indivíduo em relação a um bem ou serviço ambiental.

Segundo Van den Bergh (2000), a economia ecológica integra economia, ecologia, termodinâmica, ética e outras áreas de estudos naturais e sociais, fornecendo uma perspectiva biofísica da interação econômica e ambiental.

Ainda, Costanza et. al (2000) propuseram o conceito estratégico de precaução cética, afirmando que se deve adotar uma postura de aversão ao risco ${ }^{3}$ uma vez que a maioria dos benefícios, providos pelo meio ambiente, são insubstituíveis.

Portanto, as análises realizadas pelos riscos, calculados por meio dos valores auferidos com a aplicação da métrica sugerida por este trabalho, demonstrariam que, quanto maior o risco calculado pela métrica em cada cultura agrícola, menos o agente estaria propenso ao seu cultivo, sendo assim, o bioma tenderia a ser mais preservado, ou menos desmatado, quanto maior fosse o risco obtido pela aplicação da métrica.

Conforme Sukhdev (2010), os Métodos de Preço de Mercado (MPM), ressaltando o do Custo de Oportunidade, são mais frequentemente utilizados para se obter o valor dos serviços do meio ambiente, uma vez que as mercadorias produzidas são vendidas em um mercado bem estruturado. Segundo o mesmo autor, as preferências de custo marginal de produção, refletidas no preço de mercado,

\footnotetext{
3 Pelo conceito de aversão ao risco, utilizado por Kahneman e Hall (1998) e Viana (2005), os agentes são menos dispostos a correrem riscos quando buscam alternativas de investimentos que lhes trarão o maior retorno pelo menor risco possível, entretanto, ao correrem maiores riscos, exigem maior retorno.
} 
implicam que podem ser tomados como informações mais precisas, servindo como bons indicadores do valor do serviço do ecossistema que está sendo estudado.

Motta (1998) também relata que "a utilização de preços de mercado garante uma medida mais objetiva do valor econômico do recurso ambiental para o público em geral, uma vez que representam valores reconhecidos no mercado". O autor ainda reforça dizendo que talvez fosse esse o motivo para a maior utilização desse método e sua predileção na valoração ambiental.

Sukhdev (2010) sugere que a combinação de modelos de avaliação e uma abordagem mais acurada dos modelos de preferência podem ser o caminho a se seguir para se minimizar a incerteza técnica que permeia os estudos de valoração ambiental, especialmente no que diz respeito à credibilidade das estimativas de valores de não uso.

Conforme Huang e Odum (1991) e Pereira e Ortega (2012), os trabalhos de Odum $(1983,1988,1994,1996)$ deram início à contabilidade emergética como um novo método para integrar a concentração de matéria, energia e informação dentro de sistemas, formulando uma teoria unificadora dos sistemas de ecologia, incluindo aspectos socioeconômicos com base em princípios gerais de sistemas e nas leis da termodinâmica.

Como reforçado por Hau e Bakshi (2004), a análise emergética consegue superar a incapacidade de outros métodos existentes, de valoração ambiental, ao considerar a contribuição dos processos ecológicos no sistema econômico e, com base nos princípios da termodinâmica, teoria dos sistemas e ecologia de sistemas, realizar uma abordagem independente da valoração humana.

Ainda, segundo os mesmos autores, a análise emergética pode ser capaz de coexistir com análises econômicas, pois, enquanto a emergia fornece informações do lado da oferta, a econômica captura informações do lado da demanda.

Cavalett e Ortega (2009) dizem que a Contabilidade (ou Análise) Emergética pode determinar valores menos enviesados por julgamentos de diferentes indivíduos ao utilizar em sua base elementos das ciências exatas como a termodinâmica, podendo oferecer valores menos subjetivos.

A teoria de Simon Kuznets, segundo Dietz, Rosa e York (2012), postula que a desigualdade de renda aumenta, em um primeiro momento, conforme o produto 
interno bruto per capita (PIBpc) cresce, mas depois chega a um ponto de viragem em que, quanto mais o PIBpc aumenta, a desigualdade diminui, desenhando um "U" invertido Kuznets (1994, apud DIETZ, ROSA e YORK, 2012).

Ainda conforme os referidos autores, citando Grossman e Krueger (1995), Selden e Song (1994) e Stern, Common e Babbier (1996), essa teoria foi utilizada para tentar se prever e explicar os efeitos do crescimento econômico sobre o meio ambiente.

O Diagrama 1 exemplifica a construção da métrica, baseada no referencial teórico apresentado.

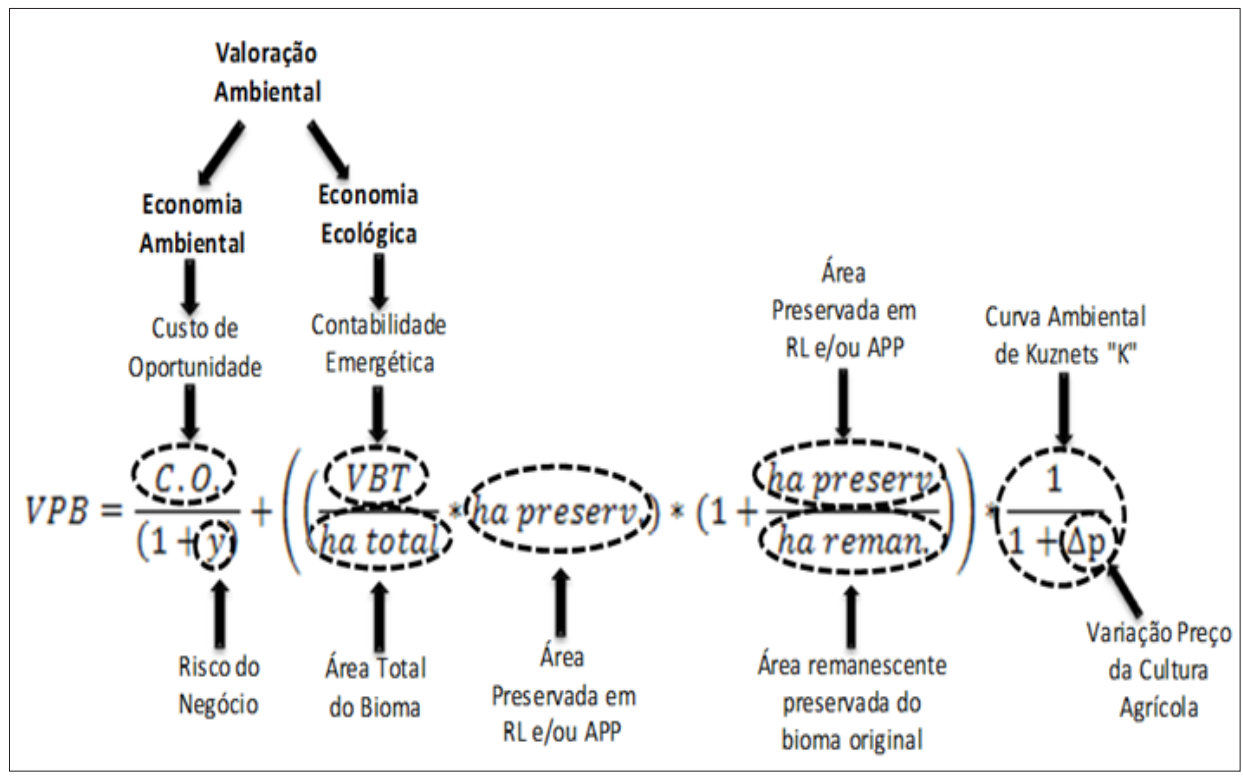

Diagrama 1. Proposta de Métrica de Valoração Ambiental.

\subsection{LIMITAÇÕES}

Miranda et al (2008) identificaram a ausência de dados cartográficos oficiais sobre áreas urbanas e industriais, tendo que realizar os cálculos das áreas de R.L.'s e APP's como se não existissem cidades, infraestrutura, sistemas energéticomineradores e outras formas de ocupação das terras que impedem seu uso agrícola. A análise emergética foi estimada, sendo que pesquisas mais precisas e acuradas da 
medição emergética de cada bioma pudessem demonstrar valores em "em Reais" maiores, como o trabalho feito por Roncon (2011) que considerou os estoques de massa e energia renovável na Mata Atlântica.

Soares-filho et al. (2014) também estudaram o impacto do Novo Código Florestal, concluindo que o passivo ambiental dos imóveis rurais no Brasil, desmatou até 2008 , foi reduzido em $58 \%$, entretanto a metodologia utilizada por Miranda et al (2008) possibilitou a utilização da métrica proposta neste trabalho em nível nacional.

A superficialidade na estimativa da emergia dos biomas pode gerar controvérsias com respeito às informações contábeis que deveriam ser isentas de viés e, portanto, confiáveis, porém não foi possível atingir a precisão pelo fato de dados mais pontuais e específicos não estarem disponíveis, entretanto acredita-se que trabalhos específicos e abrangendo todos os biomas, como o de Roncon (2011), possam tornar esses valores precisos.

Produções agrícolas foram calculadas, utilizando-se o Valor Bruto de Produção e não o Valor Líquido de Produção pela ausência de dados sobre os custos de produção agrícola, sendo que a métrica sugere a utilização do Lucro Líquido da entidade como o que foi utilizado para aplicação da métrica sobre os casos reais.

Deve-se considerar também que existem diferentes tipos de produções agrícolas como agricultura intensiva, convencional, ecológica e biológica, porém o presente trabalho considerou métodos agrícolas generalizados pela ausência de dados específicos para cada método de produção agrícola.

Pelos diferentes biomas e metodologias, utilizadas para se estimar o alcance territorial das Unidades Federais, encontram-se diferenças nos dados dispostos entre IBGE, PMDBBS (2011) e o trabalho de Miranda et al. (2008).

\section{METODOLOGIA DA PESQUISA}

Foram identificados os métodos de valoração ambiental, existentes dentro da Economia Ambiental e Economia Ecológica. Verificou-se, então, quais são as características, aplicabilidades, vantagens e desvantagens de cada método, analisando-se pelo prisma da possibilidade de o método gerar valores com menos 
incertezas e subjetividade, sendo escolhidos os métodos de Custo de Oportunidade, pela Economia Ambiental, e a Contabilidade Emergética, pela Economia Ecológica.

Do Custo de Oportunidade (CO) desconta-se uma taxa de risco do negócio, pois o indivíduo não produzirá a cultura agrícola na área preservada. Para se estimar o CO, realizaram-se cálculos baseados em Miranda et al (2008) para se estimar a quantidade de RL's e APP's no território brasileiro em cada um dos seis biomas terrestres: Amazônia, Cerrado, Mata Atlântica, Caatinga, Pampa e Pantanal. Então, os dados do Valor Bruto de Produção (VBP), das dez maiores culturas agrícolas (soja, milho, cana-de-açúcar, feijão, arroz, café, trigo, mandioca, algodão e laranja, nesta ordem, baseando-se em suas quantidades de hectares plantados), são divididos pela área plantada em que a cultura é produzida, chegando-se, assim, ao Valor Bruto de Produção por hectare (VBP). Este valor (VBP/ha) foi multiplicado pela quantidade de RL, mais a quantidade de APP do bioma determinado, chegando-se ao Custo de Oportunidade do produto agrícola que não foi produzido pela preservação em RL e APP correspondente ao bioma analisado.

Os valores auferidos com a Contabilidade Emergética foram estimados com base em Pereira e Ortega (2012). A Curva Ambiental de Kuznets foi inclusa como variável que pode influenciar no valor atribuído ao bioma, dependendo da demanda social pelo produto agrícola, produzido próximo às áreas abientais. Para estimála, foram utilizados os dados da variação dos preços de mercado de cada cultura, obtidos em consulta ao banco de dados Agrolink, um site de cotações atualizadas de preços de produtos agrícolas, mantido por iniciativa privada. Na métrica proposta, as variáveis dos biomas referentes à área remanescente, área total original e área preservada em APP's, ou conservada em RL, também foram consideradas.

Os dados de área remanescente e preservada foram obtidos no IBAMA (Instituto Brasileiro do Meio Ambiente e dos Recursos Naturais Renováveis), e, baseando-se no trabalho de Miranda et al (2008), estimou-se a área preservada em RL e APP. Após, fizeram-se aplicações da métrica em todo o território brasileiro, sendo necessário, consultando-se o site do IBGE (2012), utilizar os valores brutos de produção das culturas e área plantada. Os resultados foram, então, analisados, utilizando-se os valores referentes aos cinco anos/hectare, considerando destes os valores mínimos, máximos, médios e o coeficiente de variação ou risco.

Não foram encontrados dados de fontes oficiais governamentais com 
séries históricas dos preços dos produtos agrícolas em uma média nacional, como encontrado no site Agrolink (2012), mantido por iniciativa privada. Ainda que existam dados disponíveis no referido site, alguns estão incompletos, por exemplo, quando foram pesquisados os preços de arroz, cana e laranja, não se encontravam os valores de 2005 a 2007.

\subsection{PROPOSTA DE MÉTRICA DE VALORAÇÃO AMBIENTAL}

A métrica desenvolvida pelo trabalho baseia-se nos seguintes parâmetros:

$$
\begin{array}{ccc}
1^{\mathrm{a}} & 2^{\mathrm{a}} & 3^{\mathrm{a}} \\
\mathrm{RPB}>\mathrm{CO} & \mathrm{RPB}=\mathrm{CO} & \mathrm{RPB}<\mathrm{CO}
\end{array}
$$

Em que RPB = Remuneração pela Preservação do Bioma e CO = Custo de Oportunidade.

Na primeira e na segunda condição, a premissa é a de que o agente ficaria satisfeito pelo ato de manter a área nativa se a remuneração (recompensa) pela preservação do bioma fosse maior ou igual ao seu custo de oportunidade, pois compensaria preservar já que não haveria o risco da agricultura e teria o valor da remuneração garantido.

Já na terceira condição, o agente não ficaria satisfeito com a manutenção da área a ser preservada ou conservada visto que, se pudesse explorar comercialmente no campo de atuação da empresa, seu custo de oportunidade seria maior que a remuneração pela preservação, ou seja, a remuneração que estiver sendo oferecida ao agente preservador deve servir de estímulo à preservação de determinado bioma. Se esta não for superior ao valor de preservação do bioma, o indivíduo não se sentirá motivado a preservar.

Para se estimar o Valor de Preservação do Bioma (VPB), dois métodos de valoração ambiental são somados em uma mesma métrica. Pela economia ambiental utiliza-se o método de Custo de Oportunidade e, pela economia ecológica, o método de Contabilidade Emergética.

As duas metodologias podem facilitar o processo de tomada de decisões, 
oferecendo aos agentes informações mais tempestivas, objetivas e menos enviesadas possíveis, dando um passo na possibilidade de definição dos benefícios econômicos que a preservação ambiental pode proporcionar, portanto, a equação proposta segue exemplo:

$$
V P B=a+b
$$

A mensuração pelo método de Custo de Oportunidade, representada na equação 1 por " $a a$ ", está de acordo com os métodos de valoração, sugeridos pela Economia Ambiental, porém valora o bioma apenas se este tiver alguma aproximação com o mercado econômico existente ou, de acordo com a abordagem do estado de preferência, já a variável "b" representa a mensuração feita pela Contabilidade Emergética e será explicada mais à frente. Portanto, na primeira parte do VPB, "a" seria igual ao valor do Custo de Oportunidade (CO) do agente.

$$
a=\mathrm{C} . \mathrm{O} \text {. }
$$

O custo de oportunidade do agente (CO) é o lucro líquido por hectare no ano base de análise, o lucro líquido é aquele evidenciado na demonstração contábil do resultado do período, multiplicado pela quantidade de hectare preservado dentro da propriedade, representado na equação 3.

CO = (Lucro Líquido por hectare * quantidade de hectare preservado) $\quad$ Equação (3)

Portanto,

$a=$ (Lucro Líquido por hectare * quantidade de hectare preservado) Equação (4)

Deste Custo de Oportunidade é descontada a taxa de risco do negócio. O desconto de uma taxa de risco, referente ao negócio, por exemplo, da produção de cana-de-açúcar, deve-se ao fato de, já que o indivíduo não produzirá cana-de-açúcar 
na área preservada, RL ou APP, ele não estará correndo o risco inerente ao negócio em que está inserido. Portanto,

$$
\begin{array}{ll}
a=(\text { Lucro Líquido por hectare * quantidade de hectare preservado }) /(1+y)= & \text { Equação }(5) \\
a=\text { C. } 0 . /(1+y) & \text { Equação }(6)
\end{array}
$$

Em que: $y$ - taxa de risco referente ao negócio.

Supondo-se que um agente possua, no momento atual, uma possibilidade de lucro líquido de $\$ \$ 100,00$ por hectare de uma cultura agrícola e tenha intenção de aumentar seus rendimentos, aumentando sua área plantada. Em sua propriedade existem 10 ha de certo bioma nativo, suponha-se que pudesse desmatar este bioma, possibilitando o ganho de mais $\mathrm{R} \$ 1.000,00$. Porém lhe é oferecido esse mesmo valor, apenas descontado o risco do próprio negócio, já que ele não exercerá a atividade, sendo esse valor então de, por exemplo, $\mathrm{R} \$ 90,00$ por hectare para que não desmate o bioma, mantendo-o preservado, perfazendo um total, então, de $\mathrm{R} \$$ 900,00 .

No ano seguinte houve aumento na possibilidade de lucro de mais $\mathrm{R} \$$ 50,00 por hectare cultivado, passando, então, o potencial de lucro líquido a ser de $R \$ 150,00$ por hectare, sendo um total, se pudesse desmatar todos os 10 ha do bioma nativo, de $\mathrm{R} \$ 1.500,00$. O agente agora poderia estar mais insatisfeito com a manutenção do bioma já que vislumbra maiores lucros com sua produção agrícola e, então, para que se sinta recompensado por não poder aumentar sua área plantada, são lhe oferecidos, por exemplo, $\mathrm{R} \$ 130,00$, valor esse já descontado o risco do negócio, sendo um total pelos 10 ha de $\mathrm{R} \$ 1.300,00$.

Com o aumento do lucro líquido, ou do custo de oportunidade, o Valor de Preservação do Bioma aumentou (VPB), porém, do ponto de vista do agente agricultor, o bioma passou a gerar mais insatisfação, já que aquele tenderia a buscar maior lucratividade, desmatando para cultivar, ou seja, nesse caso, quanto maior o VPB, maior a propensão ao desmatamento ou menor a propensão à preservação.

Ainda, o lucro líquido por hectare poderia diminuir para $\mathrm{R} \$ 90,00$ no ano seguinte e, então, se o agricultor pudesse desmatar seus 10 ha de bioma preservado, 
poderá auferir $\mathrm{R} \$ 900,00$ e não mais os $\mathrm{R} \$ 1.000,00$ iniciais. Sendo assim, com a diminuição do lucro líquido, o bioma passou a ficar menos propenso à degradação, já que o agricultor tenderia a estar desestimulado ao desmatamento, pois o lucro seria menor.

Entretanto, pela visão da Economia Ecológica, o bioma tem um valor intrínseco, ou seja, mesmo que uma área ambiental não possa ter uma aproximação com o mercado ou o valor capturado pela preferência dos indivíduos, ainda assim o bioma deve ser valorado, propondo-se neste trabalho utilizar o método de Análise/ Contabilidade Emergética para se valorar cada bioma em seu todo.

A Contabilidade Emergética, baseando-se na ciência exata da termodinâmica, traz valores mais objetivos e, possivelmente, menos carregados de vieses e de subjetividades do que outros métodos de valoração, caminhando de acordo com a Contabilidade Financeira tradicional que prima por valores mais objetivos, livres de erros ou vieses relevantes e que demonstre adequadamente aquilo que se propõe a representar. Portanto, a parte referida na métrica como " $b$ " seria

$$
\mathrm{b}=\mathrm{VTB}
$$

em que $:$ VTB $=$ Valor Total do Bioma.

O VTB, estimado pela Contabilidade Emergética, é o valor total de cada bioma, devendo, portanto, ser dividido pela extensão territorial original total em hectares de cada bioma referente para que se possa estimar qual o valor dos hectares preservados pelo agente.

Por exemplo, supondo-se que o VTB de um bioma nativo seja de R\$ $1.000 .000,00$ e sua extensão territorial original total seja de $1.000 \mathrm{ha}$, sendo assim, o valor por hectare desse bioma seria de $\mathrm{R} \$ 1.000,00$. Se um agente mantém em sua propriedade 10 ha em preservação, seria possível estimar que ele possua $\mathrm{R} \$$ 10.000,00 desse bioma.

Então, a equação 7 ficaria:

$b=($ VTB $/$ ha total $) *$ ha preserv. Equação (8)

Em que $:$ ha total $=$ hectare total original do bioma e ha preserv. $=$ hectare preservado pelo agente. 
Ainda, para se trazer mais informação à métrica, afirma-se que o indivíduo que opta pela preservação em sua propriedade poderia ser recompensado por seu esforço, aumentando, assim, o valor da preservação, à medida que a área original do bioma vai sendo desmatada. Ao se dividir o hectare preservado pela quantidade original de hectare de todo o bioma, obtém-se um valor percentual que, ao multiplicar (VBT/ha total) * ha preserv., aumentaria o valor préestabelecido do bioma, conferindo uma bonificação ao agente preservador. Assim,

$$
b=(((\text { VTB } / \text { ha total }) * \text { ha preserv. }) *(1+(\text { ha preserv. } / \text { ha reman. })) \text { Equação (9) }
$$

Em que : ha reman. - hectare remanescente do bioma.

Ainda, determinada necessidade de demanda social poderia influenciar no valor atribuído ao bioma, fazendo com que a opção por aumentar a produção em detrimento da preservação seja priorizada.

Assim, uma variável, por exemplo, "k", seria atribuída à equação para considerar fatores de demanda diversos como produção de alimento, construção de moradia, produção de energia elétrica etc. Baseandose na Teoria da Curva Ambiental de Kuznets, "U" invertido, essa variável deve afetar somente a parte da equação sobre o Valor Total do Bioma $(($ VTB $/$ ha total $) *$ ha preserv. $) *(1+$ (ha preserv./ha reman. $))$.

Dessa maneira, a variável "k" representaria uma curva de demanda e oferta pelo produto agrícola ou mesmo aos seus derivados, o que afetaria inversamente o valor do bioma, pois, quanto maior a demanda por determinado produto agrícola, menor é a preservação ambiental já que seriam necessárias maiores áreas para produção. Entretanto o desenvolvimento tecnológico pode auxiliar a maior produção agrícola dentro da mesma área de cultivo, como observado com a Revolução Verde, ocorrida no Brasil na década de 1990, segundo Barros (2010) e Goodman, Sorj e Wilkinson (1990), podendo não ter aumentado áreas desmatadas.

Porém, para utilização do presente estudo, será considerada a variação dos preços de cotações de cada produto agrícola de um ano para outro, como uma proxy de oferta e demanda, apresentando-se sugestão, a final deste trabalho, para 
pesquisas futuras na tentativa de melhor apurar a variável "k", aproximando-a das premissas da teoria do "U" ambiental invertido de Kuznets. Portanto,

$$
b=(((\text { VTB } / \text { ha total }) * \text { ha preserv. }) *(1+(\text { ha preserv. } / \text { ha reman. }))) * k \text { Equação }(10)
$$

Para que se possa atender ao mercado, se o preço do produto agrícola aumentar, então "k" deve diminuir o valor do bioma, refletindo, assim, que este tenderia a ter um valor menor para o mercado já que se vislumbrariam maiores lucros, aumentando-se a área de cultivo e a necessidade de atender a determinada demanda social. Caso contrário, se o preço diminuir, então " $k$ " deve aumentar o valor do bioma, refletindo que o mercado tenderia a manter a área do bioma, já que não vê interesse econômico em aumentar sua área de produção agrícola ou não há necessidade de atender a determinada demanda social.

Dessa forma, inverte-se a variável "k", sendo

$$
\mathrm{k}=1 / 1+\Delta \mathrm{p}
$$

Em que " $p$ " é a variação dos preços dos produtos agrícolas de um ano para o outro.

Se a demanda aumentar, ou a oferta cair, ou ocorrerem os dois fatos ao mesmo tempo, o preço do produto agrícola aumentará, portanto, com variação positiva de um ano para outro.

1. Demanda $\uparrow /$ Oferta ou Demanda/Oferta $\downarrow \quad$ ou Demanda $\uparrow /$ Oferta $\downarrow \Rightarrow \mathrm{R} \$ \uparrow(\Delta+)$

Mas, se a demanda cair, ou a oferta aumentar, ou ocorrerem os dois fatos ao mesmo tempo, o preço do produto agrícola cairá, portanto, com variação negativa de um ano para outro.

2. Demanda $\downarrow /$ Oferta $\quad$ ou $\quad$ Demanda/Oferta $\uparrow \quad$ ou Demanda $\downarrow /$ Oferta $\uparrow \Rightarrow \mathrm{R} \$ \downarrow(\Delta-)$

Dessa forma, a variável "k" pode assumir um valor entre -1 e infinito de 
acordo com a variação dos preços dos produtos agrícolas. $\mathrm{O}$ preço de um produto agrícola poderia, teoricamente, desvalorizar a 0 (100\%), portanto, uma variação negativa, então,

se $1 /(1+k)$ com $\mathrm{k}=-1$ então $\mathrm{b}=((\mathrm{VTB} /$ ha total $) *$ ha preserv. $) *(1+$ (ha preserv. / ha reman.)).

E a métrica seria representada pelas partes "a" mais "b", apresentadas anteriormente na equação 1 .

$$
V P B=a+b
$$

Sendo "a" igual ao Custo de Oportunidade, descontado o risco, e "b", o valor do bioma mensurado pela contabilidade emergética.

$$
V P B=\{C .0 . /(1+y)\}+\{((V T B / \text { ha total }) * \text { ha preserv. }) *(1+(\text { ha preserv. } / \text { ha reman } .))\} \text { Equação (13) }
$$

Em outro caso, os preços dos produtos agrícolas podem subir, teoricamente, infinitamente, assim, o VPB tenderá a 0 .

Se $1 /(1+k) \quad$ com $\mathrm{k} \rightarrow \infty$, então $\mathrm{VPB}=$ $(($ VTB $/$ ha total $) *$ ha preserv. $) *(1+$ (ha preserv./ha reman. $)) \rightarrow 0$.

E a métrica ficaria representada somente pela parte "a" da equação, o Custo de Oportunidade.

$$
V P B=a=C . O . /(1+y)
$$

A lógica é que, se o preço, por exemplo, do arroz, sobe, pode ser que a demanda pelo produto subiu ou a oferta diminuiu, e, portanto, o VPB deverá ser menor, gerando maior insatisfação pela obrigatoriedade de preservar. Por outro lado, se o preço diminui, é provável que, pela lei de mercado, ou a demanda diminuiu ou a oferta aumentou e, assim, não precisando atender ao mercado, o indivíduo se sentisse estimulado a preservar pelo maior valor do VPB.

Assim, pela parte da métrica representada por "b", se o preço do produto agrícola sobe, pode ser que a demanda pelo produto subiu ou a oferta diminuiu e, portanto, o VPB deverá ser menor, expressando que os agentes estariam menos 
propensos a se satisfazerem com a preservação do bioma, priorizando a produção da cultura agrícola. Por outro lado, se o preço diminui, é provável que, pela lei de mercado, ou a demanda diminuiu ou a oferta aumentou e, assim, não precisando atender ao mercado, o indivíduo se sentisse estimulado a preservar pelo maior valor do VPB, estando o bioma mais propenso a ser preservado.

Então, a segunda parte da métrica, a parte "b", seria

$b=\{(($ VTB $/$ ha total $) *$ ha preserv. $) *(1+($ ha preserv./ha reman. $)) *(1 /(1+\Delta p))\}$ Equação $(15)$

Assim, a métrica para Valor de Preservação do Bioma apresenta-se da seguinte maneira:

Métrica de Valoração Ambiental Proposta

$$
\begin{aligned}
& V P B=\{C .0 . /(1+y)\}+\{((V T B / \text { ha total }) * \text { ha preserv. }) *(1+(\text { ha preserv. } / \text { ha reman } .)) \\
&*(1 /(1+\Delta p))\}
\end{aligned}
$$

A justificativa para se considerar a soma do Custo de Oportunidade com o Valor Bioma Total (Contabilidade Emergética) está na busca da complementariedade da Economia Ecológica e Ambiental, pois, se não há nenhum interesse econômico em determinada área de preservação, poder-se-ia considerar essa área fora dos processos de decisões econômicos (pela visão da Economia Ambiental). Enquanto que, por outro lado, não quer dizer que somente pelo fato de a área de preservação não possuir interesse econômico significaria que ela não possui nenhum valor por si só, utilizando, para isso, a visão da Economia Ecológica.

O agente preservador fica preocupado apenas com o que é de seu conhecimento e, tendo um preço tabelado para cada bioma, especificado pelo VTB, ele pode apenas estimar o valor de hectare que possui em preservação e somar ao seu custo de oportunidade, que é de seu conhecimento, e, portanto, visualizar de forma mais clara o valor que deveria ser remunerado pela preservação. 


\subsection{APLICAÇÃO DA MÉTRICA E ANÁLISE}

Para se verificar a aplicação da métrica e obter valores para os biomas, foram utilizados os seis biomas terrestres brasileiros (Amazônia, Cerrado, Mata Atlântica, Caatinga, Pantanal e Pampas) e as dez culturas agrícolas (soja, milho, cana-deaçúcar, feijão, arroz, café, trigo, mandioca, algodão e laranja) que mais desmataram, seguindo a proxy de quantidade de hectares plantados. Os dados de cada variável da equação foram sintetizados em uma tabela para facilitar sua aplicação sobre cada caso.

Quadro 1. Tabela para aplicação da métrica

\begin{tabular}{|l|}
\hline \multicolumn{1}{|c|}{ Dados } \\
\hline Área Total do Bioma (ha) \\
\hline Remanescente Bioma (ha) \\
\hline Reserva Legal/APP (ha preserv.) \\
\hline$\Delta$ Preço \\
\hline Valor Total do Bioma (R\$) \\
\hline Valor Bioma/hectare (R\$/ha) \\
\hline Área Plantada (ha) \\
\hline Valor Bruto Produção $(\mathrm{R} \$)$ \\
\hline Valor Bruto Produção/ha $(\mathrm{R} \$ /$ ha) \\
\hline Custo de Oportunidade \\
\hline Y \\
\hline C.O. (total) \\
\hline Valor Bioma \\
\hline K \\
\hline V.B. (total) \\
\hline Total \\
\hline Em 5 anos \\
\hline Em 5 anos/hectare \\
\hline
\end{tabular}

Para entendimento das variáveis, segue o Quadro 2 explicativo no qual são destacadas as variáveis apresentadas em cada parágrafo: 
Quadro 2. Variáveis utilizadas pela métrica

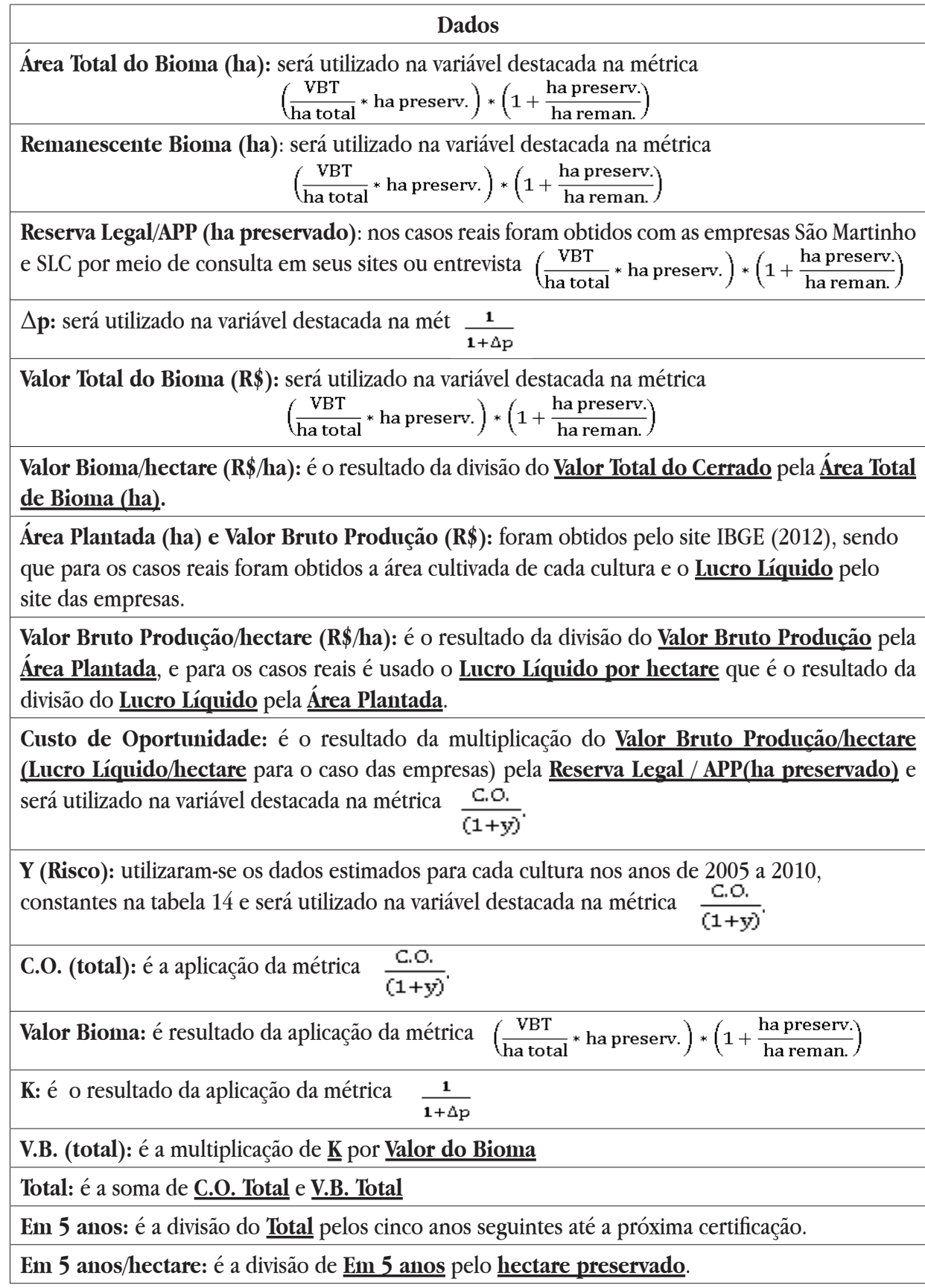

Fonte: Elaborada pelos autores. 
A métrica expressa que, se o preço do produto agrícola sobe, pode ser que a demanda pelo produto subiu ou a oferta diminuiu e, portanto, o VPB deverá ser menor, expressando que o bioma estaria menos propenso à geração de satisfação por ter que preservar, visto que poderia ter melhor resultado se pudesse priorizar a produção da cultura agrícola. Por outro lado, se o preço diminui, é provável que, pela lei de mercado, ou a demanda diminuiu ou a oferta aumentou e, assim, não precisando atender ao mercado, o indivíduo se sentisse estimulado a preservar pelo maior valor do VPB, estando o bioma mais propenso a criar satisfação pelo ato de preservar.

Para se facilitar a análise dos dados, foram utilizados os valores referentes aos cinco anos/hectare de Aplicação da Métrica em nível nacional. A ausência de valores deve-se ao fato de algumas culturas não serem produzidas próximas aos respectivos biomas e os dados das médias nacionais de preços dos produtos agrícolas não estarem disponíveis ou não haver os valores brutos de produção.

Comparar o valor do bioma entre cada cultura agrícola demonstra que o bioma com maior valor, referente à determinada cultura, estaria mais propenso à preservação do que comparado ao valor referente à outra cultura com menor valor.

$\mathrm{O}$ valor auferido com a métrica proposta representaria a intenção, ou satisfação, do agente em preservar ou não determinada área ambiental, pois qualquer alteração do preço do produto agrícola no mercado refletiria no valor do bioma, por exemplo, se o preço agrícola aumentar, o agente tenderá a produzir mais em detrimento da preservação, ou seja, o valor do bioma será menor, pelo contrário, se o preço baixar, o agente tenderá a não produzi-lo e, assim, estará mais propenso à preservação, ou seja, o valor do bioma será maior. Por exemplo, obter que o valor do cerrado, no ano de 2010, era de $\mathrm{R} \$ 647,01$ em cinco anos por hectare, referente à produção de cana-de-açúcar e $\mathrm{R} \$ 345,02$, no mesmo ano, referente à produção de soja, demonstra que o bioma cerrado tem menos valor para a produção de soja do que para a de cana-de-açúcar, ou seja, estaria mais valorizado, portanto, o agente estaria mais propenso a se satisfazer pela preservação do bioma Mata Atlântica sob a cultura de cana-de-açúcar do que para a produção de soja. 
Tabela 2. Resultados em R\$ (reais) da aplicação da métrica "Em 5 anos / hectare" nos biomas Amazônia e Cerrado em 2005-2010

\begin{tabular}{|c|c|c|c|c|c|c|c|c|c|c|c|c|}
\hline \multirow{2}{*}{$\begin{array}{l}\text { Produtos } \\
\text { Agricolas }\end{array}$} & \multicolumn{6}{|c|}{ Amazônia } & \multicolumn{6}{|c|}{ Cerrado } \\
\hline & 2005 & 2006 & 2007 & 2008 & 2009 & 2010 & 2005 & 2006 & 2007 & 2008 & 2009 & 2010 \\
\hline 50ja & 321,66 & 257,4 & 310,38 & 457,31 & 466,41 & 367,60 & 253,35 & 206,90 & 241,24 & 412,76 & 408,76 & 345,02 \\
\hline Wilho & 237,23 & 239,71 & 255,98 & 332,42 & 304,06 & 230,94 & 158,77 & 151,75 & 202,93 & 259,86 & 217,28 & 200,96 \\
\hline Cana & - & - & . & 633,09 & 772,01 & 768,33 & - & - & - & 444,83 & 600,14 & 647,01 \\
\hline Feijäo & 583,76 & 273,36 & 229,06 & 381,83 & 304,21 & 305,03 & 287,44 & 248,71 & 244,23 & 490,70 & 321,45 & 390,06 \\
\hline Arroz & - & . & - & 332,11 & 349,50 & 345,35 & $\therefore$ & . & . & 291,36 & 286,85 & 275,85 \\
\hline Café & 322,89 & 300,08 & 411,10 & 502,90 & 437,32 & 495,15 & 666,17 & 933,77 & 744,09 & $1.070,37$ & 940,65 & $1.223,93$ \\
\hline Irigo & 157,46 & 301,38 & 338,85 & 265,58 & . & 491,37 & 53,67 & 210,46 & 300,92 & 324,42 & 305,63 & 323,29 \\
\hline Nandioca & 431,03 & 533,76 & 485,31 & 569,16 & 648,57 & 616,75 & 376,16 & 423,57 & 406,90 & 502,19 & 572,35 & 483,65 \\
\hline Algodăo & $1.115,94$ & 393,42 & 964,98 & 866,17 & $1.085,55$ & $1.094,59$ & 630,32 & 336,75 & 845,35 & 801,35 & $1.013,53$ & $1.241,70$ \\
\hline Laranja & . & - & - & 610,85 & 902,12 & $1,125,57$ & - & - & - & $1.171,72$ & $1,169,42$ & $1.377,83$ \\
\hline Total & $3.169,97$ & $2,299,15$ & $2,995,65$ & $4.951,47$ & $5.269,75$ & $5.840,70$ & $2,425,88$ & 2511,91 & 2985,66 & $5.769,57$ & $5.836,06$ & $6.509,30$ \\
\hline
\end{tabular}

Pela Tabela 3, a Mata Atlântica no ano de 2008 tem um valor de $\$$ \$07,65 em cinco anos por hectare, referente à produção de soja, e $\mathrm{R} \$ 175,93$, no mesmo ano sob a produção de trigo, demonstrando que o bioma Mata Atlântica teria menos valor sob produção de trigo do que para a produção de soja, estando, assim, o agente mais propenso a se satisfazer pela preservação do bioma Mata Atlântica sob a cultura de soja do que para o cultivo de trigo.

Tabela 3. Resultados em R\$ (reais) da aplicação da métrica "Em 5 anos / hectare" nos biomas Mata Atlântica e Caatinga em 2005-2010

\begin{tabular}{|c|c|c|c|c|c|c|c|c|c|c|c|c|}
\hline \multirow{2}{*}{$\begin{array}{l}\text { Produtos } \\
\text { Agricolas }\end{array}$} & \multicolumn{6}{|c|}{ Mata-Atlântica } & \multicolumn{6}{|c|}{ Caatinga } \\
\hline & 2005 & 2006 & 2007 & 2008 & 2009 & 2010 & 2005 & 2006 & 2007 & 2008 & 2009 & 2010 \\
\hline Soja & 201,64 & 203,63 & 270,46 & 407,65 & 358,81 & 333,69 & 255,61 & 178,29 & 251,00 & 429,40 & 368,95 & 299,23 \\
\hline Milho & 207,56 & 189,00 & 270,83 & 338,66 & 263,21 & 292,97 & 78,89 & 92,27 & 88,06 & 130,14 & 114,33 & 108,36 \\
\hline Cana & - & - & - & 398,16 & 558,44 & 604,77 & - & . & - & 379,92 & 578,95 & 615,67 \\
\hline Feijão & 239,92 & 218,72 & 177,07 & 473,09 & 279,36 & 299,68 & 90,61 & 92,05 & 81,94 & 131,26 & 86,12 & 99,55 \\
\hline Arroz & - & - & - & 655,36 & 710,16 & 672,50 & $\cdot$ & - & - & 275,87 & 262,25 & 197,33 \\
\hline Café & 562,30 & 778,15 & 751,43 & 961,93 & 817,61 & 996,36 & 508,62 & 626,08 & 600,58 & 739,63 & 774,79 & 756,89 \\
\hline Trigo & 137,11 & 130,96 & 234,93 & 175,93 & 183,02 & 259,07 & 416,71 & 394,46 & 503,77 & 535,37 & 640,00 & 418,18 \\
\hline Mandioca & 460,81 & 565,88 & 575,03 & 646,94 & 748,88 & 813,14 & 206,23 & 237,57 & 242,80 & 276,06 & 331,31 & 269,48 \\
\hline Algodão & 115,16 & 78,87 & 228,02 & 171,09 & 144,80 & 150,28 & 322,06 & 262,66 & 666,17 & 710,85 & 594,27 & 709,83 \\
\hline Laranja & - & - & - & $1.097,53$ & $1.075,59$ & $1.284,24$ & - & - & - & 533,01 & 880,95 & 784,65 \\
\hline Total & $1.924,49$ & $2,165,23$ & $2.507, \pi$ & $5.326,34$ & $5.139,88$ & $5.706,72$ & 1876,72 & $1.883,38$ & $2,434,31$ & $4.141,51$ & $4,631,91$ & $4.259,18$ \\
\hline
\end{tabular}


Outra comparação entre os valores verificados com a aplicação da métrica em nível nacional é entre os diferentes biomas referentes a uma mesma cultura agrícola, o que demonstra que o bioma com maior valor estaria mais propenso à preservação, diante da maior satisfação do agente, do que o outro com menor valor, referente à mesma cultura agrícola.

Tomando-se como referência a produção de trigo, na Tabela 4, o bioma Pantanal seria valorado a $\mathrm{R} \$ 160,99$ no ano de 2007 , enquanto o bioma Pampa teria um valor de $\mathrm{R} \$ 179,57$, no mesmo ano, sob a mesma produção agrícola, podendo estar, portanto, o bioma Pantanal menos propenso à preservação sob a produção de trigo, no ano de aplicação da métrica, do que o bioma Pampa.

Tabela 4. Resultados em R\$ (reais) da aplicação da métrica "Em 5 anos / hectare" nos biomas Pantanal e Pampa em 2005-2010

\begin{tabular}{|c|c|c|c|c|c|c|c|c|c|c|c|c|}
\hline \multirow{2}{*}{\begin{tabular}{|l|} 
Produtos \\
Agricolas
\end{tabular}} & \multicolumn{6}{|c|}{ Pantanal } & \multicolumn{6}{|c|}{ Pampa } \\
\hline & 2005 & 2006 & 2007 & 2008 & 2009 & 2010 & 2005 & 2006 & 2007 & 2008 & 2009 & 2010 \\
\hline Soja & 225,87 & 194,13 & 260,89 & 378,41 & 373,05 & 313,29 & 77,85 & 163,90 & 227,33 & 302,20 & 322,80 & 306,86 \\
\hline Milho & 157,13 & 164,82 & 200,75 & 255,04 & 186,67 & 189,43 & 96,84 & 152,47 & 234,46 & 289,31 & 198,76 & 278,73 \\
\hline Cana & - & . & - & 434,57 & 595,47 & 709,57 & - & - & - & 478,98 & 627,36 & 772,04 \\
\hline Feeiläo & 316,93 & 245,29 & 208,59 & 478,63 & 264,25 & 389,78 & 157,91 & 198,94 & 142,97 & 317,80 & 312,46 & 227,87 \\
\hline Arroz & . & . & - & 368,79 & 410,29 & 387,09 & - & . & - & 710,49 & 753,99 & 699,37 \\
\hline Café & 314,88 & 447,53 & 502,02 & 396,18 & 271,86 & 489,42 & - &. & - &. &. & - \\
\hline Trigo & 115,53 & 119,7 & 160,99 & 161,75 & 178,75 & 189,74 & 114,72 & 102,66 & 179,57 & 180,85 & 181,54 & 224,65 \\
\hline Mandioca & 524,57 & 649,92 & 670,02 & 774,57 & 904,05 & 817,45 & $1.139,15$ & 1389,01 & $1.203,76$ & $1.431,71$ & $1.566,91$ & $1.754,03$ \\
\hline Algodăo & 830,48 & 344,7 & 830,53 & 815,54 & 941,80 & $1.040,32$ & - & - & - & - & - & - \\
\hline 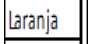 & - & . & - & $1.492,56$ & $1.623,71$ & $1.454,40$ & - & . & - & $1.104,78$ & $1.170,26$ & $1.289,68$ \\
\hline Total & $2.485,39$ & $2.166,24$ & $2.833,79$ & $5.556,04$ & $5.749,90$ & $5,980,50$ & $1.586,47$ & 2006,97 & $1.988,09$ & $4.816,13$ & $5.134,08$ & $5.553,23$ \\
\hline
\end{tabular}

Por exemplo, em 2008 o bioma amazônico poderia valer $\mathrm{R} \$ 457,31$ sob a produção de soja, mas $\mathrm{R} \$ 502,96$, sob a produção de café, podendo estar menos propenso à preservação sob a produção de soja do que sob a produção de café.

O bioma amazônico, no exemplo, sob a produção de feijão obteve um valor maior em 2005 do que em 2007. Seguindo com a interpretação, portanto, em 2005, o bioma estaria mais propenso à preservação do que em 2007.

Outra análise a ser feita é sobre os cálculos das variações de riscos. A tabela a seguir resume os valores de riscos calculados para cada cultura agrícola e cada bioma, sendo Amazônia (AM), Cerrado (CE), Mata Atlântica (MA), Caatinga (CA), Pantanal (PAN) e Pampas (PAM). 
Tabela 5. Valores dos riscos das culturas em cada bioma durante 2005 a 2010

\begin{tabular}{l|c|c|c|c|c|c|c|c|c|c|} 
& Soja & Milho & Cana & Feijão & Arroz & Café & Trigo & Mandioca & Algodão & Laranja \\
\hline AM & 0,2309 & 0,1564 & 0,1093 & 0,3765 & 0,0265 & 0,2070 & 0,3907 & 0,1486 & 0,2990 & 0,2935 \\
\hline CE & 0,2876 & 0,2003 & 0,1876 & 0,2880 & 0,0280 & 0,2206 & 0,4206 & 0,1569 & 0,3839 & 0,0965 \\
\hline MA & 0,2864 & 0,2117 & 0,2083 & 0,3681 & 0,0413 & 0,1938 & 0,2756 & 0,2035 & 0,3419 & 0,0995 \\
\hline CA & 0,3034 & 0,1864 & 0,2417 & 0,1840 & 0,1712 & 0,1587 & 0,1940 & 0,1639 & 0,3696 & 0,2451 \\
\hline PAN & 0,2636 & 0,1807 & 0,2383 & 0,3187 & 0,0535 & 0,2331 & 0,1975 & 0,1874 & 0,2994 & 0,0583 \\
\hline PAM & 0,4161 & 0,3580 & 0,2340 & 0,3316 & 0,0400 & - & 0,2821 & 0,1612 & - & 0,0789 \\
\hline
\end{tabular}

O Gráfico 1 é representação das informações apresentadas na Tabela 5.

\section{Análise pelo Risco}

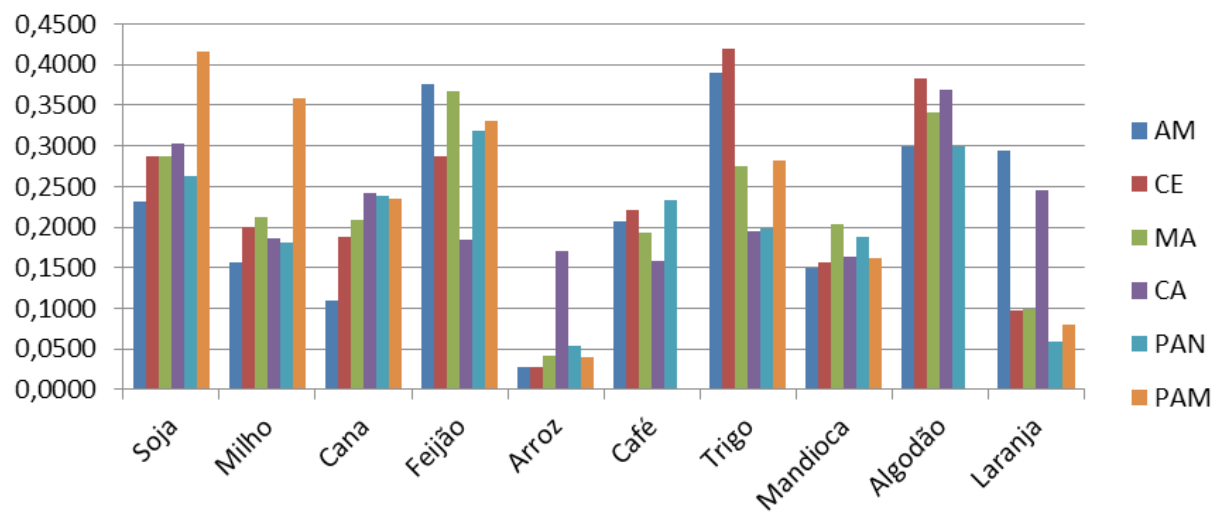

Gráfico 1. Variação dos valores de risco das culturas agrícolas em cada bioma durante 2005 a 2010.

Pelo conceito de aversão ao risco mencionado anteriormente, sugere-se a interpretação de que, dado o maior risco observado pelas culturas de soja, feijão, trigo e algodão, seria provável que os biomas tenderiam a ser mais preservados, já que os agentes estariam menos dispostos a correrem os riscos do negócio, mantendo, assim, os biomas preservados diante dessa cultura agrícola.

Percebem-se, pela análise gráfica, uma concentração dos biomas com valores de risco alto pelas culturas de soja, feijão, trigo e algodão e uma concentração dos biomas com valores de risco menores pela cultura de arroz.

Por outro lado, a cultura do arroz apresentou menor risco e, assim, os agentes estariam mais dispostos a praticarem a cultura do arroz, colocando os 
biomas mais propensos ao desmatamento diante dessa cultura agrícola, sendo que os biomas Caatinga, Pantanal e Pampa seriam os menos degradados e os biomas Mata Atlântica, Cerrado e Amazônia, os mais degradados sob a cultura de arroz.

\section{CONCLUSÕES}

A contabilidade das entidades requer que os valores mensurados possam ser confiáveis, aceitos e relevantes aos usuários das informações, sendo que a base de mensuração deve transmitir com maior fidelidade possível a realidade de determinada transação ou outros eventos, o que nem sempre é possível por erros, vieses ou ausência de técnicas que capturem adequadamente as informações que correspondam a tais transações e eventos.

A métrica proposta estudou e adaptou algumas das alternativas de valoração ambiental existentes para oferecer a possibilidade de se estimar com maior acurácia o valor que pode ser atribuído à preservação, ou conservação, de áreas de RL's e APP's sob o prisma das empresas.

Foram conciliados, na métrica, os métodos de Custo de Oportunidade e Contabilidade Emergética, pois estes estariam mais de acordo com as premissas contábeis de mensuração dos eventos e transações empresariais e poderiam facilitar o processo de valoração, porém foram acrescidas variáveis, considerandose riscos do negócio, custo/benefício, áreas preservadas dos biomas em RL, APP's e remanescentes, variação dos preços das culturas e Curva Ambiental de Kuznets.

Trata-se de uma proposta inovadora, que permite refletir sobre o valor do meio ambiente e a pertinência de agregar informações sobre ele ao patrimônio que está à disposição e sob a responsabilidade das empresas. A Contabilidade e Valoração Ambiental podem desempenhar papel de filtro sobre as variadas metodologias de valoração, contingente, hedônica, custos de viagem, entre outros, quando faz uso de suas premissas de compreensibilidade, relevância, confiabilidade e comparabilidade na mensuração.

Portanto, valorar determinada área, neste estudo de R.L.'s e APP's, com uma mensuração mais confiável, com menos erros, vieses, subjetividade e incertezas 
poderia habilitar um mercado ambiental de preservação para remunerar o agente, ou entidade, que se dispõe à preservação ambiental.

A capacidade da nova métrica de valoração de encobrir todo o território brasileiro e até mesmo regiões menores sugere sua facilidade de aplicação, demandando, portanto, menos custos e chegando a um valor que, seguindo as premissas contábeis de valoração, possa ter aceitabilidade maior.

Ao tentar evidenciar os valores de áreas ambientais preservadas por uma entidade, a contabilidade forneceria, aos agentes financeiros e tomadores de decisões, informações sobre o desempenho, riscos e oportunidades ambientais de determinada empresa, as quais podem ser objeto de comparação entre companhias, e, assim, estimular a preservação por meio de um mercado remunerador como previsto no Novo Código Florestal. Entretanto unicamente demonstrar esses valores poderia não estimular a preservação, até mesmo poderia ter resultados contrários a essa intenção, sendo, portanto, necessário o rigor da lei em seu cumprimento e, assim, orientar indivíduos para manutenção e preservação ambiental.

Portanto, não se pode imaginar que apenas o PSA poderia incentivar a preservação, sendo necessária que haja fiscalização eficaz e cumprimento da lei por parte de agentes desmatadores.

Com dados mais precisos sobre a valoração emergética, os custos de produção agrícola e maior precisão na mensuração das RL's e APP's, poder-se-iam obter estimativas mais próximas da realidade. É também necessário considerar as externalidades, sejam negativas ou positivas, na valoração ambiental, pois as ações antrópicas alteram a emergia original de maneira particular em cada tipo de bioma. Nesse sentido, para futuros estudos, poderão ser considerados, dentro da métrica proposta por este presente trabalho, essas externalidades e os diferentes tipos de métodos agrícolas como agricultura intensiva, convencional, ecológica e biológica, conservando-se a facilidade de aplicação da métrica sobre diversos casos diferentes.

Outra sugestão de trabalho futuro é tentar, sob o enfoque positivista, uma abordagem com modelos estatísticos em todos os métodos de valoração, verificando quais deles estariam dentro das premissas contábeis de mensuração. Outro passo futuro é a contabilização emergética completa e acurada de cada bioma nacional de modo a se obter um valor de referência nacional de cada bioma. 


\section{REFERÊNCIAS}

AGROLINK. Disponível em <http://www.agrolink.com.br/Default.aspx > . Acesso em: 02 mar. 2012.

BEDER, S. Environmental economics and ecological economics: the contribution of interdisciplinarity to understanding, influence and effectiveness. Environmental Conservation, Australia, v, 38, p. 140-150, 2011.

BOTTON, L. O. S. O Desmatamento das Florestas Nativas como Decorrência das Falhas de Mercado. 2008. Disponível em: < http://www.egov.ufsc.br/portal/ conteudo/o-desmatamento-das-florestas-nativas-como-decorr\%C3\%AAncia-dasfalhas-de-mercado > . Acesso em: 2 set. 2012.

BRÄUER, I. et al. The Use of Market Incentives to Preserve Biodiversity. 2006. Disponível em: <http://www.ecologic.de/download/ projekte/1750-1799/1750/1750-11_use_of_market_incentives_to_preserve_ biodiversity.pdf $>$. Acesso em: 14 out. 2011

CAVALETT, O.; ORTEGA, E. Emergy, nutrients balance, and economic assessment of soybean production and industrialization in Brazil. Journal of Cleaner Production, v. 17, p. $762-771,2009$.

CHIABAI, A.; TRAVISI, C. M.; MARKANDYA, A.; DING, H.; NUNES, P. A. L. D. Economic Assessment of Forest Ecosystem Services Losses: Cost of Policy Inaction. Revista: Environmental Resource Economics, 2011.

COSTANZA, R.; DALY, H. E.; FOLKE, C.; HAWKEN, P.; HOLLING, C. S.; MCMICHAEL, A. J.; PIMENTEL, D.; RAPPORT, D. Managing our environmental portfolio. BioScience, v. 50, n. 2 , p. $149-155,2000$.

DIETZ, T.; ROSA, E. A.; YORK, R. Environmentally efficient well-being: Is there a Kuznets curve? Journal: Applied Geography, v. 31, p. 21-28, 2012

FERREIRA, A. C. S. Contabilidade ambiental: uma informação para o desenvolvimento sustentável. 3. ed. São Paulo: Atlas, 2011. 
GROSSMAN, G.; KRUEGER, A. Economic growth and the environment. Quarterly Journal of Economics, v. 110, p. 353-377, 1995.

HAU, J. L.; BAKSHI, B. R. Promise and problems of emergy analysis. Ecological Modelling, Ohio State University, Columbus, Ohio, v. 178, p. 212-225, 2004.

HUANG, S.; ODUM, H.T. Ecology and economy: emergy synthesis and public policy in Taiwan. Environmental Management, v. 32, p. 313-333, 1991.

IBGE. Sistema IBGE de recuperação automática - SIDRA 2012. Disponível em: $<$ http://www.sidra.ibge.gov.br/bda/pesquisas/CD2010ETRD/default.asp $>$. Acesso em: 14 jul. 2012.

PMDBBS. Projeto de monitoramento do desmatamento dos biomas brasileiros por satélite 2011. Disponível em: < http://siscom.ibama.gov.br/monitorabiomas/index. htm >. Acesso em: 28 out. 2012.

KAHNEMAN, D.; HALL, R. Aspects of investor psychology-beliefs, preferences and biases investment advisors should know about. Journal of Portfolio Management, v. 24, n.4, 1998.

MIRANDA, E. E.; CARVAlHO, C. A.; SPADOTTO, C. A.; HOTT, M. C.; OSHIRO, O. T.; HOLLER, W. A. Alcance Territorial da Legislação Ambiental e Indigenista. Campinas: Embrapa Monitoramento por Satélite, 2008. Disponível em: < http://www.alcance.cnpm.embrapa.br/> . Acesso em: 13 out. 2011.

MOTTA, R. S. Manual para Valoração Econômica de Recursos Ambientais. Ministério do Meio Ambiente, dos Recursos Hídricos e da Amazônia Legal. 1998.

ODUM, H.T. Systems Ecology: An Introduction. John Wiley, NY, p. 644. 1983. (revised in 1994. Ecological and General Systems: An Introduction to Systems Ecology. Univ. Press of Colo., P.O. Box 849, Niwot 80544).

ODUM, H.T. Self-organization, transformity and information. Science, v. 242, p. 1132-1139, 1988. 
ODUM, H.T. Ecological and General Systems: An Introduction to Systems Ecology. University Press of Colorado, USA, 1994.

ODUM, H.T. Environmental accounting, emergy and decision-making. New York: J. Wiley, 1996. 370p.

PEREIRA, L.; ORTEGA, E. A modified footprint method: The case study of Brazil. Ecol. Indicat., 2012. DOI:10.1016/j.ecolind.2011.06.016.

RONCON, T. J. Valoração ecológica de áreas de preservação permanente. 2011 (Dissertação de Mestrado) - UFSCar, São Carlos, 2011.

SELDEN, T. M.; SONG, D. Environmental Quality and Development: Is there a Kuznets Curve for Air Pollution Emissions? Journal of Environmental, 1994.

STERN, D. I.; COMMON, M. S.; BABBIER, E. B. Economic growth and environmental degradation. World Development, v. 24, p. 1151-1160, 1996.

SUKHDEV, P.; TEEB. The Economics of Ecosystems and Biodiversity: Mainstreaming the Economics of Nature: A synthesis of the approach, conclusions and recommendations of TEEB. 2010.

VAN DEN BERGH, J. C. J. M. Ecological economics: themes, approaches, and differences with environmental economics. Tinbergen Institute Discussion Paper, Department of Spatial Economics, Free University: Amsterdam, 2000.

VIANA, Ricardo J. A. L. O efeito da miopia e a aversão à perda nas decisões de risco. 2005. Dissertação (Mestrado em Economia) - Departamento de Economia, Universidade de Brasília, Brasília, DF.

Recebido em: 17 de março de 2015 Aceito em: 23 de novembro de 2016 